\title{
UPAYA GURU DALAM PELAKSANAAN HOME-BASED LEARNING BERBASIS DARING DI SAAT PANDEMI COVID-19
}

\section{TEACHERS' EFFORTS IN THE IMPLEMENTATION OF HOME- BASED LEARNING BASED ONLINE IN THE TIME OF COVID-19}

\author{
Clara Febria Mooy ${ }^{1 *}$, Wiputra Cendana ${ }^{2}$ \\ 1,2 Pendidikan Sekolah Dasar Universitas Pelita Harapan Tangerang, Indonesia \\ ${ }^{* 1}$ clara.febriamooy@gmail.com \\ ²wiputra.cendana@uph.edu
}

\begin{tabular}{ll}
\hline \multicolumn{1}{c}{ Article Info } & Abstract \\
\hline & $\begin{array}{l}\text { In the midst of the COVID-19 pandemic there have been changes in various fields of buman life, } \\
\text { including in the field of education. For this reason, learning that is usually carried out in schools has }\end{array}$ \\
$\begin{array}{l}\text { Historical Articles } \\
\text { Submitted: 2021-05-02 }\end{array}$ & $\begin{array}{l}\text { now turned to online home-based learning (HBL), because people are probibited from being outside the } \\
\text { Revised: 2021-06-11 }\end{array}$ \\
Issued: 2021-06-30 & provide solutions to teachers who have problems in implementing synchronous learning which is not \\
& effective. The solution given is the implementation of asynchronous learning so that students can learn \\
& learning materials independently and learning objectives can be achieved. This type of asynchronous \\
Keywords: Home-Based & learning is successfully implemented because it is effective and can help students learn without a fixed \\
Learning, Affective, & time and place so that students can access learning as needed and can be repeated until students \\
Synchronous Learning, & understand well the learning material being taught. Suggestions for teachers are to apply effective \\
Asynchronous Learning & learning methods used in online HBL so that students can understand the learning material delivered
\end{tabular}

Kata kunci:

Pembelajaran Dari

Rumah, Afektif,

Pembelajaran Daring,

Pembelajaran Luring

\section{Abstrak}

Di tengah pandemi COVID-19 telah terjadi perubahan di berbagai bidang kehidupan manusia, termasuk di bidang pendidikan. Untuk itu pembelajaran yang biasanya dilakukan di sekolah kini telah beralih ke pembelajaran berbasis rumahan (HBL) online, karena masyarakat dilarang berada di luar rumah dalam waktu yang lama dan berada di suatu tempat dalam skala besar. Tujuan penulisan jurnal ini adalah untuk memberikan solusi kepada guru yang mengalami kendala dalam melaksanakan pembelajaran sinkron yang tidak efektif. Solusi yang diberikan adalah penerapan asynchronous learning agar siswa dapat mempelajari materi pembelajaran secara mandiri dan tujuan pembelajaran dapat tercapai. Pembelajaran asinkron jenis ini berhasil dilaksanakan karena efektif dan dapat membantu siswa belajar tanpa waktu dan tempat yang tetap sehingga siswa dapat mengakses pembelajaran sesuai kebutuhan dan dapat diulang hingga siswa memahami dengan baik materi pembelajaran yang diajarkan. Saran bagi guru adalah menerapkan metode pembelajaran yang efektif digunakan dalam HBL online agar siswa dapat memahami materi pembelajaran yang disampaikan oleh guru.

\section{PENDAHULUAN}

Selama pandemi COVID-19 terdapat perubahan-perubahan mendadak dalam setiap bidang kehidupan manusia, termasuk bidang pendidikan. Salah satu tindakan yang dilakukan pihak sekolah agar kegiatan belajar mengajar tetap berlangsung di tengah pandemi COVID-19 yaitu menerapkan home-based learning (HBL). Home-based learning yang dilakukan oleh persekolahan 
selama pandemi COVID-19 ini tidak terlepas dari penggunaan teknologi sebagai pendukung pembelajaran. Teknologi memiliki peran penting dalam bidang pendidikan sebagai alat atau sarana yang digunakan untuk melaksanakan pembelajaran.

Selama pandemi COVID-19 sekolah-sekolah yang ada di Indonesia termasuk TK, menggunakan beberapa platform digital seperti Google Classroom, Microsoft Teams, dan Zoom untuk melaksanakan kegiatan belajar mengajar selama pandemi COVID-19 agar siswa dapat belajar dari rumah masing-masing. Komunikasi antar siswa dan guru sebagai media pendidikan dilakukan melalui media komunikasi seperti gawai dan internet, hal ini membantu guru untuk memberikan pengajaran kepada siswa dan membantu siswa untuk dapat belajar tanpa perlu melakukan kelas tatap muka di sekolah bersama guru (Jamun, 2018).

Selama menjalani Program Pengalaman Lapangan 2 (PPL 2) penulis melihat bahwa teknologi memiliki peran penting dalam berlangsungnya bome-based learning yang dilakukan selama pandemi COVID-19 ini. Penulis menggunakan platform Microsoft Teams sebagai sarana untuk menjalankan PPL 2 dan mengajar siswa Kindergarten 3 (K3). Selama menjalankan PPL 2, pembelajaran yang diselenggarakan sekolah adalah HBL berbasis daring yang dilaksanakan secara synchronous dan asynchronous. Selama proses pelaksanaan synchronous learning penulis menemukan masalah yang terjadi di dalam kelas yang mana terdapat siswa yang bermain sendiri atau menghilang dari layar kamera ketika guru sedang menjelaskan materi pembelajaran. Selain itu, ketika guru memberikan waktu kepada siswa untuk mengerjakan worksheet terdapat siswa yang mengerjakannya diluar instruksi yang diberikan oleh guru karena tidak memperhatikan instruksi dengan baik. Hal ini membuat kelas menjadi kurang efektif dan membuat durasi pembelajaran tidak cukup karena guru harus memberikan instruksi tambahan diluar alokasi waktu yang ditetapkan dalam rancangan pembelajaran. Untuk menyikapi hal ini diperlukan adanya asynchronous learning sebagai sarana bagi siswa untuk dapat mempelajari materi pembelajaran diluar synchronous learning agar siswa lebih memahami materi pembelajaran yang diajarkan oleh guru dan juga dapat melatih siswa untuk belajar mandiri.

Berdasarkan kendala yang dialami oleh penulis dalam pelaksanaan PPL 2 maka penulis membuat rumusan masalah berikut: 1) Apa upaya yang dilakukan guru agar siswa dapat memahami materi pembelajaran dengan baik selama HBL berbasis daring? 2) Apa upaya yang dilakukan guru agar tujuan pembelajaran tercapai? Penelitian ini bertujuan untuk memberikan solusi kepada guru yang mengalami kendala dalam pelaksanaan HBL. Penelitian ini juga ditujukan kepada guru yang sedang aktif mengajar di saat pandemi COVID-19 sehingga HBL dapat terlaksana dengan baik sesuai dengan tujuan pembelajaran yang ingin dicapai oleh guru.

\section{Efektivitas Synchronous Learning}

Synchronous learning adalah model pembelajaran yang dilakukan secara online yang mana interaksi antar siswa terjadi pada waktu yang sama, secara bersamaan (Sistek-Chandler, 2020). Hofmann (2004) mengatakan bahwa synchronous learning mengacu pada instruksi yang dipimpin oleh fasilitator (guru) secara real time, umumnya melalui internet. Synchronous learning biasa dilakukan melalui aplikasi seperti Zoom, Google Meet, Microsoft Teams, Whats App dalam waktu yang bersamaan namun dari tempat yang berbeda. Selama synchronous learning berlangsung, guru dan siswa tidak bertemu secara fisik namun mereka bertemu secara virtual selama penyampaian materi pembelajaran (Negash \& Wileox, 2008). Guru harus mampu mengelola kelas dan memelihara kondisi pembelajaran yang optimal untuk mencapai tujuan pembelajaran (Gultom \& Saun, 2016). Keadaan ini menjadi salah satu tantangan bagi guru dalam pelaksanaan synchronous learning karena guru dan siswa sama-sama belum terbiasa dan harus beradaptasi dengan HBL berbasis daring ini. 
Efektivitas dalam pembelajaran mempengaruhi pemahaman yang dimiliki siswa mengenai materi pembelajaran yang diberikan serta menjadi kunci dari tercapainya tujuan pembelajaran. Dalam menciptakan pembelajaran yang efektif, terdapat beberapa permasalahan yang muncul. Pertama, guru masih belum memilih strategi pembelajaran yang paling efektif. Kedua, guru tidak merencanakan pembelajaran dengan baik. Ketiga, guru tidak mampu menciptakan lingkungan belajar yang aman dan nyaman bagi siswa (Gultom \& Saun, 2016). Synchronous learning dapat efektif jika dalam pelaksanaannya guru dan siswa dapat memanfaatkan teknologi informasi dan komunikasi yang ada secara optimal sebagai alat bantu dalam proses pembelajaran (Hanum, 2013).

Konsentrasi belajar merupakan suatu tindakan menyisihkan atau menghalau segala sesuatu yang tidak berhubungan dengan objek yang dipelajari agar daya pikiran dapat terpusat pada pembelajaran (Ikawati, 2016). Motivasi diri yang kurang kuat di dalam diri siswa untuk mengikuti synchronous learning bisa menjadi faktor siswa tidak mengikuti pembelajaran sesuai dengan yang diharapkan oleh guru. Faktor kedua yang menyebabkan siswa kurang fokus dalam pembelajaran yaitu suasana rumah atau tempat siswa melaksanakan pembelajaran yang tidak kondusif sehingga membuat siswa sulit fokus (Putria, Maula, \& Uswatun, 2020). Selain itu manajemen kelas yang buruk juga bisa mempengaruhi keadaan kelas menjadi tidak efektif (Gultom \& Saun, 2016). Oleh karena itu guru harus mengetahui strategi pembelajaran seperti apa yang efektif dilaksanakan dalam pembelajaran (Rachmah, 2012). Permasalahan ini bisa saja terjadi karena penyajian materi yang diberikan oleh guru tidak menarik bagi siswa terlebih karena guru dan siswa masih belum terbiasa dengan HBL berbasis daring, sehingga guru harus merancang pembelajaran yang menarik dan melibatkan siswa secara aktif dalam setiap proses pembelajaran yang mana siswa tidak hanya mendengarkan penjelasan dari guru saja tetapi juga melakukan tindakan seperti mengerjakan sesuatu berkaitan dengan materi pembelajaran (Rachmah, 2012).

Pelaksanaan HBL berbasis during tidak bisa hanya mengandalkan synchronous learning saja karena tidak semua siswa dapat memahami materi pembelajaran secara keseluruhan dalam kurun waktu 50 menit, untuk itu perlu adanya blended learning yang menggabungkan antara synchronous learning dan asynchronous learning agar siswa dapat mempelajari kembali materi pembelajaran secara mandiri diluar synchronous learning berdasarkan pilihan waktu yang tepat oleh siswa. Dalam pelaksanaan synchronous learning juga pastinya terdapat kendala teknis mengenai teknologi yang digunakan ataupun koneksi yang tidak stabil, sehingga tujuan pembelajaran tidak bisa tercapai dengan baik.

\section{Pemanfaatan Asynchronous Learning sebagai Pendukung Synchronous Learning dalam HBL}

Asynchronous learning merupakan salah satu model pembelajaran yang pelaksanaannya biasa dilakukan dengan memanfaatkan teknologi masa kini. Asynchronous learning terjadi di luar interaksi simultan antar guru dan siswa, pertukaran informasi tidak terbatas pada tempat dan waktu yang sama (Sistek-Chandler, 2020). Asynchronous learning merupakan model pembelajaran yang berpusat pada siswa dan dapat dilaksanakan melalui teknologi online (Pablos, Tennyson, \& Lytras, 2015). Asynchronous learning adalah pembelajaran yang bisa dilakukan melalui e-mail, forum diskusi, webcasting, file-file video atau audio (Rusli, Hermawan, \& Supuwiningsih, 2017). Jadi, asynchronous learning memungkinkan siswa untuk mengatur pembelajarannya sendiri, pada jadwal yang independen, dan menghabiskan lebih banyak waktu untuk persiapan dan refleksi bila diperlukan (Sistek-Chandler, 2020). Hal ini dapat memberikan kontribusi pada produk pembelajaran yang lebih mendalam. Penulis menyimpulkan bahwa asynchronous learning ini dapat menjadi salah satu solusi terhadap pelaksanaan synchronous learning yang tidak efektif. Melalui asynchronous learning siswa dapat mempelajari materi pembelajaran dengan durasi yang lebih panjang karena tidak ada patokan waktu dalam pelaksanaannya. Selain itu, dalam asynchronous learning materi pembelajaran 
yang akan dibahas dalam synchronous learning sudah terlebih dahulu diberikan sehingga siswa dapat mempelajarinya terlebih dahulu sebagai persiapan mengikuti synchronous learning.

Konsentrasi belajar merupakan suatu tindakan menyisihkan atau menghalau segala sesuatu yang tidak berhubungan dengan objek yang dipelajari agar daya pikiran dapat terpusat pada pembelajaran (Ikawati, 2016). Motivasi diri yang kurang kuat di dalam diri siswa untuk mengikuti synchronous learning bisa menjadi faktor siswa tidak mengikuti pembelajaran sesuai dengan yang diharapkan oleh guru. Faktor kedua yang menyebabkan siswa kurang fokus dalam pembelajaran yaitu suasana rumah atau tempat siswa melaksanakan pembelajaran yang tidak kondusif sehingga membuat siswa sulit fokus (Putria, Maula, \& Uswatun, 2020). Selain itu manajemen kelas yang buruk juga bisa mempengaruhi keadaan kelas menjadi tidak efektif (Gultom \& Saun, 2016). Oleh karena itu guru harus mengetahui strategi pembelajaran seperti apa yang efektif dilaksanakan dalam pembelajaran (Rachmah, 2012). Permasalahan ini bisa saja terjadi karena penyajian materi yang diberikan oleh guru tidak menarik bagi siswa terlebih karena guru dan siswa masih belum terbiasa dengan HBL berbasis daring, sehingga guru harus merancang pembelajaran yang menarik dan melibatkan siswa secara aktif dalam setiap proses pembelajaran yang mana siswa tidak hanya mendengarkan penjelasan dari guru saja tetapi juga melakukan tindakan seperti mengerjakan sesuatu berkaitan dengan materi pembelajaran (Rachmah, 2012).

Pelaksanaan HBL berbasis during tidak bisa hanya mengandalkan synchronous learning saja karena tidak semua siswa dapat memahami materi pembelajaran secara keseluruhan dalam kurun waktu 50 menit, untuk itu perlu adanya blended learning yang menggabungkan antara synchronous learning dan asynchronous learning agar siswa dapat mempelajari kembali materi pembelajaran secara mandiri diluar synchronous learning berdasarkan pilihan waktu yang tepat oleh siswa. Dalam pelaksanaan synchronous learning juga pastinya terdapat kendala teknis mengenai teknologi yang digunakan ataupun koneksi yang tidak stabil, sehingga tujuan pembelajaran tidak bisa tercapai dengan baik.

\section{Efektivitas Asynchronous Learning sebagai Pendukung Synchronous Leaming}

Tindakan yang dilakukan guru dalam memberikan solusi atas synchronous learning yang tidak efektif adalah melaksanakan asynchronous learning dengan memberikan video pembelajaran singkat yang membahas materi pembelajaran yang diberikan dalam synchronous learning. Berdasarkan penelitian yang dilakukan oleh Agustiningsih (2015), video pembelajaran dapat memvisualisasikan pesan yang ingin disampaikan dalam materi pembelajaran. Dada \& Alkali (2019) dalam penelitiannya menyatakan bahwa penerapan asynchronous learning dapat membantu siswa untuk merefleksikan gagasan mereka sendiri dan mendorong siswa untuk berpikir lebih kritis.

\section{METODE}

Webster's new international dalam (Anshori \& Iswati, 2009) mengatakan bahwa penelitian adalah penyelidikan untuk mencari fakta dan prinsip untuk menetapkan sesuatu dengan cara yang kritis dan penuh kehati-hatian. Peneliti menggunakan metode kualitatif deskriptif untuk melakukan penelitian kali ini. Penelitian kualitatif adalah penelitian yang dilakukan tidak berdasarkan data statistik tetapi menggunakan pendekatan naturalistik guna memahami fenomena dan eksplorasi pada kondisi yang sama (Anggito \& Setiawan, 2018). Penelitian kualitatif deskriptif menggunakan sampel, pengumpulan data, teknik analisis data yang beragam (Rosyada, 2020). Sampel yang terdapat dalam penelitian adalah siswa Kindergarten 3. Data yang digunakan yaitu RPP, refleksi guru, dan lembar hasil observasi kelas yang dilaksanakan selama 6 minggu oleh peneliti secara daring. Data yang didapatkan kemudian dikaji menggunakan beberapa teori dan jurnal penelitian yang relevan. 


\section{HASIL PENELITIAN}

Berdasarkan data yang dikumpulkan oleh peneliti, terdapat masalah yang dialami selama pelaksanaan synchronous learning yang mana terdapat siswa yang bermain dan menghilang dari layar kamera saat guru sedang menjelaskan materi pembelajaran. Masalah diatas memberikan dampak terhadap proses pembelajaran, diantaranya: 1) Siswa tidak mengikuti pembelajaran dengan konsentrasi; dan 2) Pelaksanaan synchronous learning menjadi tidak efektif. Maka dari itu, dalam pelaksanaan HBL berbasis daring, guru tidak bisa hanya mengandalkan synchronous learning untuk melaksanakan pembelajaran dikelas. Terdapat dua tipe pembelajaran yang digunakan dalam pelaksanaan HBL yaitu synchronous dan asynchronous learning. Penggabungan kedua tipe ini dilakukan agar pembelajaran dapat berjalan dengan maksimal sehingga setiap siswa dapat memahami materi pembelajaran yang sedang dipelajari di kelas dan tujuan pembelajaran yang direncanakan oleh guru juga tercapai._Asynchronous learning didasarkan pada teori konstruktivisme yaitu pembelajaran yang berpusat pada siswa, pendekatan ini menggabungkan belajar mandiri dengan interaksi asynchronous untuk memfasilitasi pembelajaran jarak jauh (Shahabadi \& Uplane, 2015). Strategi atau solusi yang diberikan oleh guru untuk mengatasi permasalahan di atas yaitu dengan memanfaatkan asynchronous learning sebagai pembelajaran pendukung synchronous learning yang mana siswa dapat mempelajari materi pembelajaran secara mandiri tanpa adanya batasan waktu dan tempat dalam pelaksanaannya. Upaya yang dilakukan guru dalam pelaksanaan asynchronous learning ini adalah dengan memberikan video pembelajaran singkat yang berisi materi pembelajaran yang dipelajari siswa dalam synchronous learning.

\section{PEMBAHASAN}

Memasuki tahun 2020 terdapat tantangan dan perubahan yang dialami masyarakat Indonesia, terkhusus pada bulan Maret 2020 yang mana Indonesia pertama kalinya mengumumkan bahwa terdapat beberapa masyarakat Indonesia yang dinyatakan positif mengidap COVID-19. Dengan demikian Kementerian Pendidikan dan Kebudayaan mengeluarkan surat edaran No 4 tahun 2020 tentang pelaksanaan kebijakan pendidikan dalam masa darurat penyebaran Coronavirus Disease (COVID-19), bahwa seluruh siswa wajib belajar dari rumah dan pelaksanaan ujian nasional dibatalkan demi keamanan seluruh warga sekolah (Kemdikbud, 2020). Home-Based Learning (HBL) berbasis daring adalah metode pembelajaran yang dilakukan dirumah masing-masing dan menggunakan teknologi dan internet sebagai sarana pelaksanaannya. HBL berbasis daring ini merupakan salah satu metode yang digunakan dalam bidang pendidikan agar kegiatan belajar mengajar tetap berlangsung meskipun harus dilaksanakan di rumah masingmasing. Teknologi yang dapat digunakan dalam melaksanakan HBL ini dapat berupa komputer, laptop, atau telepon genggam serta internet sebagai penghubung antar guru dan siswa dalam melaksanakan HBL sehingga siswa dan guru masih bisa merasakan kebersamaan dalam HBL meskipun tidak bisa bertemu secara langsung.

Pembahasan diatas menunjukkan bahwa dalam bidang pendidikan memang diperlukan adanya asynchronous learning sebagai wadah bagi siswa untuk dapat belajar dan memenuhi kebutuhannya sebagai siswa. Di tengah pandemi COVID-19 Asynchronous learning merupakan salah satu tipe pembelajaran efektif yang dapat diterapkan oleh guru karena pelaksanaannya fleksibel, sehingga siswa yang belum memahami materi pembelajaran dapat belajar secara mandiri. Jika siswa memiliki pertanyaan atau kurang memahami materi pembelajaran selama mengikuti asynchronous learning, siswa dapat mengajukan pertanyaan melalui kolom komentar pada Microsoft Teams atau aplikasi lain yang digunakan dalam HBL berbasis daring ini. Tujuan dari penelitian ini adalah untuk memberikan solusi kepada guru yang memiliki kendala dalam pelaksanaan HBL 
berbasis daring sehingga guru dapat menerapkan asynchronous learning agar siswa yang tidak fokus atau tidak dapat memahami materi pembelajaran sepenuhnya dalam synchronous learning dapat mempelajarinya kembali dalam asynchronous learning.

\section{SIMPULAN}

Asynchronous learning memiliki peran penting dalam efektivitas implementasi HBL online, sehingga siswa dapat mempelajari kembali materi pembelajaran yang diajarkan dalam synchronous learning dan tujuan pembelajaran tercapai. HBL online akan efektif dan berhasil jika implementasi synchronous dan asynchronous learning dapat berjalan beriringan. Guru perlu menyiapkan pembelajaran yang menarik dan variatif agar siswa dapat terus semangat dalam belajar. Penerapan blended learning menuntut peran guru untuk dapat menyiapkan berbagai metode pembelajaran dan media pembelajaran agar siswa tidak bosan dan terus semangat dalam mengeksplorasi berbagai materi pembelajaran yang dikemas. Upaya guru dalam menerapkan HBL online akan memberikan hasil yang baik jika guru dan siswa dapat bekerja sama dengan baik dalam pelaksanaannya.

\section{REFERENSI}

Agustiningsih. (2015). "Video" sebagai Alternatif Media Pembelajaran dalam Rangka Mendukung Keberhasilan Penerapan Kurikulum 2013 di Sekolah Dasar. Pancaran, Vol. 4, No. 1, 58.

Anggito, A., \& Setiawan, J. (2018). Metodologi Penelitian Kualitatif. Sukabumi: CV Jejak.

Anshori, M., \& Iswati, S. (2009). Metodologi Penelitian Kuantitatif. Surabaya: Pusat Penerbitan dan Percetakan UNAIR.

Dada, E., \& Alkali, A. (2019). An Investigation into the Effectiveness of Asynchronous and Synchronous E-Learning Mode on Students' Academic Performance in National Open University (NOUN), Maiduguri Centre. I.J Modern Education and Computer Science, 60.

Gultom, E., \& Saun, S. (2016). The Role of Classroom Management in Creating an Effective English Learning. Journal of English Language Teaching, 19.

Hanum, N. S. (2013). Keefektifan E-Learning sebagai Media Pembelajaran (Studi Evaluasi Model Pembelajaran E-Learning SMK Telkom Sandhy Putra Purwokerto). Jurnal Pendidikan Vokasi, 93.

Hofmann, J. (2004). The Synchronous Trainer's Survival Guide: Facilitating Successful Live and Online Courses, Meetings, and Events. United States of America: Library of Congress Cataloging-inPublication Data.

Ikawati, M. P. (2016). Upaya Meningkatkan Konsentrasi Belajar Siswa KMS (Kartu Menuju Sejahtera) Menggunakan Konseling Kelompok bagi Siswa. Psikopedagogia, 159.

Jamun, Y. M. (2018). Dampak Teknologi Terhadap Pendidikan. Jurnal Pendidikan dan Kebudayaan Missio, Vol. 10, No. 1, 49.

Kemdikbud. (2020, Maret 24). Mendikbud Terbitkan SE tentang Pelaksanaan Pendidikan dalam Masa Darurat Covid-19. Diambil kembali dari kemdikbud.go.id: https:/ /www.kemdikbud.go.id/main/blog/2020/03/mendikbud-terbitkan-se-tentangpelaksanaan-pendidikan-dalam-masa-darurat-covid19. 
Negash, S., \& Wileox, M. (2008). E-Learning Classifications: Differences and Similarities. Handbook of Distance Learning for Real-Time and Asynchronous Information Technology Education, 4.

Pablos, P. O., Tennyson, R., \& Lytras, M. (2015). Assessing the Role of Mobile Technologies and Distance Learning in Higher Education. United State of America: IGI Global.

Putria, H., Maula, H. L., \& Uswatun, D. A. (2020). Analisis Proses Pembelajaran Dalam Jaringan (DARING) Masa Pandemi COVID-19 pada Guru Sekolah Dasar. Jurnal Basicedu Vol. 4, 864.

Rachmah, H. (2012). Strategi Pembelajaran Aktif di Sekolah Dasar. WIDYA, 9.

Rosyada, D. (2020). Penelitian Kualitatif Untuk Ilmu Pendidikan. Jakarta: Kencana.

Rusli, M., Hermawan, D., \& Supuwiningsih, N. N. (2017). Multimedia Pembelajaran yang Inovatif: Prinsip Dasar \& Model Pengembangan. Yogyakarta: Penerbit ANDI.

Shahabadi, M. M., \& Uplane, M. (2015). Synchronous and Asynchronous E-learning Styles and Academic Performance of E-learners. Procedia-Social and Behavioral Sciences, 132.

Sistek-Chandler, C. M. (2020). Exploring Online Learning Through Synchronous and Asynchronous Instructional Methods. United State of America: IGI Global. 